\title{
A Política de Quantitative Easing adotada pelo FED altera a Volatilidade dos Ativos no Brasil?
}

\section{Does the Quantitative Easing Policy adopted by the Fed change asset volatility in Brazil?}

\author{
Helberte João França Almeida* \\ Adilson Giovanini** \\ Kleverton Clovis de Oliveira Saath*** \\ Milton Biage****
}

Resumo: A crise financeira de 2008 resultou em um quadro de taxas de juros de curto prazo próximas de zero e levou vários países a adotarem políticas monetárias não convencionais com a finalidade de estabilizar o sistema financeiro e sustentar o nível da atividade econômica. Embora o objetivo do programa de compra de títulos, denominado como quantitative easing $(\mathrm{QE})$, iniciado pelo Federal Reserve (Banco Central dos Estados Unidos), fosse estimular a atividade econômica interna, seu efeito externalidade foi sentido pelos países emergentes que observaram uma elevação no fluxo de capital externo, um aumento na procura por ativos e uma apreciação da moeda nacional. Dado este contexto, o presente estudo avalia se o QE afetou a volatilidade do índice Ibovespa, do câmbio, do riscopaís, da taxa de juros dos Estados Unidos e do índice de renda fixa. Para tanto, utiliza-se de técnicas de estudos de eventos e modelos autorregressivos e generalizados autorregressivos heteroscedásticos para verificar o comportamento das variáveis consideradas. Os resultados encontrados indicam que o QE alterou a volatilidade dos ativos em alguns períodos analisados e seu início/fim modificou os retornos dos ativos.

Palavras-chave: Quantitative easing.Volatilidade. Ativos financeiros.

Abstract: The financial crisis of 2008 resulted in a short-term interest rates near zero frame and led many countries to adopt unconventional monetary policies in order to stabilize the financial system and sustain the level of economic activity. Although the purpose of the bond-buying program, known as quantitative easing $(\mathrm{QE})$, initiated by the Federal Reserve (Central Bank of the United States) is related only to domestic economic, his externality effect was felt by the emerging countries that had an increase in the flow of foreign capital, increased demand for assets and appreciation of the national currency. Given this context, the objective of this study is to evaluate whether the QE policy affected the volatility of Ibovespa index, exchange rate, country risk, US interest rates and fixed income index. Therefore, it uses the event study and auto regressive models and generalized autoregressive heteroscedastic to check the behavior of the variables considered. The results show that the

\footnotetext{
* $\quad$ Professor do Departamento de Economia e Relações Internacionais da Universidade Federal da de Santa Catarina (UFSC). E-mail: helberte.almeida@ufsc.br

** Doutor em economia, PPGECO, UFSC. E-mail: adilsoneconomia@gmail.com

*** Mestre em Economia, PPGECO, UFSC. E-mail: klevertonsaath1995@hotmail.com

**** Professor do Departamento de Economia e Relações Internacionais da Universidade Federal da de Santa Catarina (UFSC). E-mail: milton.biage@ufsc.br
} 
QE alter the volatility of the assets in some analyzed peroxides and their start / end modifies the return on assets.

Keywords: Quantitative easing.Volatility.Financial assets.

JEL Classification: E52; G15; G18.

\section{Introdução}

A crise do Subprime ${ }^{1}$ surgiu em 2007 na economia norte-americana e, posteriormente, se alastrou para outras economias ao redor do mundo. O seu efeito sobre a economia mundial foi de tamanha magnitude que ainda hoje é possível observar as suas consequências. Dados da Organização para Cooperação e Crescimento Econômico (2014) mostram que a economia mundial está enfrentando dificuldades para se recuperar desta crise.

Os países afetados pela crise adotaram políticas monetária e fiscal expansionistas para fornecer liquidez ao sistema financeiro e sustentar a demanda agregada (YELLEN, 2013). Os principais bancos centrais do mundo (Banco Central dos Estados Unidos, Banco Central da Zona do Euro, Banco Central da Inglaterra e Banco Central Japonês) cortaram suas taxas básicas de juros de curto prazo para valores próximos à zero, com a finalidade de reduzir os efeitos negativos da crise (FAWLEY; NEELY, 2013).

A redução das taxas de juros de curto prazo não resultouno aumento da taxa de crescimento do PIB. Dado que não era mais possível reduzir a taxa de juros para estimular a economia, as autoridades governamentais adotaram formas não convencionais de políticas monetárias para garantir a liquidez das operações bancárias, recuperar o funcionamento do sistema financeiro e tirar a economia da recessão (BERNANKE, 2012).

A política de compra de ativos, denominada de quantitative easing foi utilizada pelo Federal Reserve (FED) para tentar estimular a economia americana. Esta política pode ser dividida em três diferentes rodadas: QE1, QE2 e QE3. Embora cada uma destas rodadas de intervenção tivesse objetivos específicos, todas elas aumentaram a base monetária da economia americana em resposta aos desencadeamentos da crise financeira (FAWLEY; NEELY, 2013).

$1 \quad$ A crise do subprime é uma crise financeira desencadeada em 2006, a partir da quebra de instituições de crédito dos Estados Unidos, que concediam empréstimos hipotecários de alto risco (subprime loan ou subprime mortgage), arrastando vários bancos para uma situação de insolvência e repercutindo fortemente sobre as bolsas de valores de todo o mundo. A crise foi revelada ao público a partir de fevereiro de 2007, como uma crise financeira grave (para muitos economistas, a mais grave desde 1929), com possibilidades de transformar-se em crise sistêmica, entendida como uma interrupção da cadeia de pagamentos da economia global, que tenderia a atingir generalizadamente todos os setores econômicos. Portanto, um prenúncio da crise econômica de 2008 (BRESSER-PEREIRA, 2009). 
A intervenção do FED, através da compra de títulos privados, obrigou os investidores arealocarem os seus portfólios. A compra de títulos privados pelo FED influenciouna quantidade disponível do ativo para os investidores privados e no rendimento deste ativo (FRATZSCHER; DUCA; STRAUB,2013). Desta forma, os investidores foram induzidos a comprar outros ativos com maturidade mais longa, risco mais elevado e maior rendimento (JOYCE et al., 2012). As expectativas pessimistas em relação ao crescimento econômico dos Estados Unidose as baixas taxas de retorno estimularam os investidores a buscar alternativas mais atrativas de investimento em outros países.

Segundo Fratzscher, Duca e Straub (2013), os fluxos internacionais oriundos das políticas monetárias não convencionais dos países desenvolvidos ocasionaram a apreciação das moedas, bolha no preço dos ativos e desequilíbrios financeiros nos países emergentes. Ademais, Morgan (2011) estimou que $40 \%$ do aumento da base monetária realizada pelo QE1 vazou na forma de saídas de capital privado epara o QE2 esta quantidade chegou a um terço.

Diante destes fatos, o presente estudo tem as seguintes perguntas de pesquisa: $\mathrm{O} Q E$ adotado pelo banco central norte-americano afetou a volatilidade do índice Ibovespa, do câmbio, do riscopaís, dos juros dos Estados Unidose do índice de renda fixa no Brasil? Qual o tamanho do impacto? A hipótese defendida é que o QE resultou em um aumento da liquidez e em uma diminuição das taxas de retornos dos ativos como menor risco nos Estados Unidos. A taxa de juros brasileira elevada, o crescimento da economia nacionale as expectativas negativas em relação à capacidade de crescimento do PIB dos Estados Unidoscontribuíram para que uma parte dos recursos injetados pelo FED via QE fosse desviada para o Brasil.

Além desta introdução, este artigo encontra-se estruturado da seguinte forma: aseção 2 apresenta uma revisão de literatura sobre o QE. Por sua vez, a seção 3 traz a metodologia utilizada. Posteriormente, a seção 4 apresenta os resultados obtidos. Por fim, a seção 5 mostra as considerações finais sobre os resultados encontrados.

\section{Referencial}

Segundo Bernanke (2012), para realizar uma política monetária não convencional os bancos centrais podem recorrer a três classes de medidas diferentes: i) comunicar a politica monetária aos agentes econômicos, induzindo estes aacreditarem que a taxa de juros de longo prazo será baixa; ii) aumentar seu balanço patrimonial (quantitative easing); e iii) alterar a composição do seu balanço patrimonial (qualitative easing).

A expressão "quantitative easing"foi utilizada para descrever a política do Banco Central Japonês no período de 2001 a 2006. Esta política consiste na ex- 
pansão da base monetária através da compra de ativos privados. Através dela, o banco central cria moeda para comprar títulos (dívida pública, empréstimos comerciais ou ações), com o objetivo de aumentar a liquidez e estimular a economia.

A política de quantitative easing adotada na economia americana se divide em três grandes fases de intervenção. A primeira fase (QE1) tinha como objetivo agir especificamente no mercado de hipotecas, que foi o mais afetado pela crise e recuperar a confiança dos agentes econômicos. Para alcançar este objetivo, o FED comprou dívidas das agências securitizadas e ativos lastreados em hipotecas.

A segunda fase (QE2) pretendia reduzir as taxas de juros de longo prazo. Assim, o banco central comprou títulos de longo prazo, reduzindo o preço e a rentabilidade destes. Por fim, na terceira fase (QE3) o FED voltou a comprar títulos de agências securitizadas no mercado imobiliário.

Segundo Breedon, Chadha e Waters (2012), apesar do QE ser amplamente utilizado por diversos bancos centrais, a sua efetividade é questionável. O sucesso da política do QE exige que os mecanismos de transmissão da política monetária estejam funcionando. No entanto, a ocorrência da crise comprometeu as expectativas dos agentes, diminuindo a eficácia dos canais de transmissão.

A literatura econômica apresenta diversos mecanismos de transmissão da política monetária não convencional Joyce et al. (2011) afirmam que esta política atua, principalmente, através de três canais de transmissão: sinalização,balanço patrimonial e prêmio de liquidez.

No canal sinalização, os anúncios de compra dos títulos devem mostrar aos participantes do mercado o modo como a instituição vê as condições presentes e futuras da economia. Este canal deve fornecer informações sobre a trajetória futura da taxa de juros de curto prazo.

Nos períodos em que a economia não alcança determinado nível de emprego/desemprego, o banco central compra títulos e sinaliza ao mercado que a taxa de juros de curto prazo deve permanecer baixa. Os anúncios de compra de títulos do Banco Central reduzem os rendimentos esperados de longo prazo (BAUER; RUDEBUSCH, 2016).

Cabe ressaltar que o canal sinalização pode gerar efeitos positivos ou negativos sobre o preço dos ativos, o queocorre porque a taxa de juros pode sofrer uma redução no curto prazo. Este movimento também pode sinalizar alta inflação no futuro e, consequentemente, aumento da taxa de juros de longo prazo.

A compra de títulos pelos bancos centrais dos Estados Unidos e da Inglaterra influenciam diretamente a quantidade de títulos disponíveis e o rendimento destes. Os depósitos bancários, comprados como contrapartida, não podem ser considerados perfeitamente substituíveis.Como consequência, uma mudança na quantidade de um ativo específico pode levar a alterações na taxa de retorno do ativo. 
A substituição imperfeita pode explicar porque os agentes realocam os seus portfólios quando o banco central compra títulos do governo. A atuação do banco central induz os investidores a comprarem outros ativos de longo prazo, que apresentam maior rendimento. Como resultado, as famílias detentoras destes ativos observam um aumento da sua riqueza, o que pode aumentar o seu consumo corrente (JOYCE et al., 2011).

O canal de equilíbrio do portfólio é um dos principais mecanismos de transmissão da política monetária não convencional. A importância deste mecanismo de transmissão é destacada por Bernanke (2010):

As evidências [são] mais favoráveis à visão de que as compras [de títulos e outras obrigações] funcionam principalmente através do chamado portflio balance channel, a qual sustenta que uma vez que as taxas de juros de curto prazo tenham atingido zero, as compras do FED de títulos de longo prazo afetam as condições financeiras na medida em que muda as quantidades e o mix de ativos financeiros em posse do público. Especificamente, a estratégia do FED repousa na hipótese de que diferentes ativos financeiros não são substitutos perfeitos no portfólio do investidor, assim, mudanças na oferta líquida de um ativo disponível para os investidores afeta [não apenas o] seu rendimento [mas também o rendimento dos ativos] semelhantes. (BERNANKE, 2010, p. 9).

No canal da liquidez, a presença do banco central como comprador de ativos pode melhorar a funcionalidade do mercado e reduzir o prêmio de liquidez. Isto ocorre porque o QE está baseado na compra de títulos de longo prazo, o que aumenta as reservas bancárias. $\mathrm{O} Q \mathrm{QE}$ aumenta a liquidez dos investidores e diminui o prêmio de iliquidez dos títulos mais líquidos. A expansão na liquidez pode resultar em uma redução do custo da iliquidez, aumentando o rendimento nos ativos mais líquidos e não apresentando nenhum efeito nos ativos ilíquidos.

\subsection{Evidências do Impacto do Quantitative Easing}

Antes da crise do subprime, o exemplo mais proeminente de aplicação de estímulos monetários não convencionais (QE) foi o Japão. A adoção desta politica resultou em um aumento da base monetária no país. Todavia, essa não aumentou na magnitude esperada e seu efeito não foi suficiente para retirar a economia da trajetória recessiva observada no período pós-bolha. Kashyap eStein (2000) e Hosono (2006) utilizaram dados de 2000-2009 para examinar o efeito que a politica do QE, adotada pelo Banco do Japão, exerceu sobre a economia japonesa. Os 
resultados encontrados indicam que esta política exerceu uma influência elevada, positiva e estatisticamente significativa. Assim, o QE resultou no aumento da liquidez e do crédito bancário.

Após a crise do subprime, surgiu uma literatura crescente que analisa o efeito das compras de ativos pelo Banco da Inglaterra e pelo FED. Esta literatura analisa a influência exercida pelo QE sobre os mercados financeiros e, mais estritamente, sobre os mercados de obrigações governamentais. Um dos primeiros estudos que verifica o efeito do $\mathrm{QE}$ sobre as reservas federais dos Estados Unidosfoi Gagnon eSack (2011), que concluiu que as compras do FED, entre dezembro de 2008 e março de 2010, influenciaram a taxa de juros de longo prazo. Estudos posteriores, realizados por D'Amico eKing (2010) e Hamilton eWu (2012), mostraram que as intervenções do FED via QE1 reduziram as taxas de juros de médio e longo prazo. $\mathrm{O}$ anúncio do $\mathrm{QE}$, realizado pelo $\mathrm{FED}$, também teve repercussões importantes em taxas internacionais de longo prazo e no valor à vista do dólar (NEELY, 2011).

Gagnon etal. (2011), Krishnamurthy e Vissing-Jorgensen (2011), Meaning e Zhu (2011) e Joyce et al. (2012) verificaram os efeitos do quantitative easing sobre a taxa de juros dos Estados Unidos. A conclusão geral alcançada por estes autores é que o QE reduziu a taxa de juros de curto e longo prazo dos Estados Unidos. A maior redução ocorreu na primeira rodada do QE. Ademais, Joyce et al. (2012) afirma que ainda não existem evidências suficientes sobre a politica do QE no longo prazo.

Outra linha de pesquisa é formada pelos autores que buscam avaliar o efeito do QE sobre as variáveis reais da economia. Esta linha de pesquisa reúne autores como Lenza, Pill e Reichlin (2010), Baumeister e Benati (2010), Kapetanios et al. (2012), Schenkelberg e Watzka (2013) e Lyonnet e Werner (2012). Estes autores utilizam diferentes conjuntos de dados e abordagens econométricas. Em suma, os resultados encontrados mostram que o $\mathrm{QE}$ aumentou as taxas de crescimento do produto e da inflação para os países analisados.

Além destes trabalhos, existem outros estudos que buscam avaliar o impacto que o QE exerce sobre as taxas de retorno dos títulos corporativos e sobre os rendimentos do capital. Krishnamurthy eVissing-Jorgensen (2011) e Neely (2010) mostraram que o QE1 exerceu um forte impacto sobre os títulos corporativos. Glick eLeduc (2012) concluem que o QE1 reduziu os preços das commodities em $11 \%$, com efeito concentrado em commodities relacionadas à energia e metais preciosos. Por sua vez, Joyce et al. (2011), investigam o impacto da política de flexibilização quantitativa do Banco da Inglaterra nos preços dos ativos do Reino Unido. O estudo é baseado na análise da reação dos preços no mercado financeiro. Os resultados encontrados demostram que as compras de ativos financiados pela emissão de reservas do banco central podem ter reduzido os rendimentos de títulos do governo em cerca de 100 pontos base, no longo prazo. 
Outros trabalhos buscam avaliar o efeito transbordamento do QE sobre os países emergentes. Neste grupo de trabalho encontram-se os estudos de Hausman eWongswan (2011) e Neely (2010). Hausman eWongswan (2011) mostram que o $\mathrm{QE}$ alterou a taxa de juros corrente e futura de muitos países emergentes. Neely (2010) utiliza a metodologia de estudo de eventos e conclui que os anúncios do FED, relacionados ao QE, provocaram uma depreciação do dólar frente ao dólar canadense e ao yen.

Embora a literatura econômica reconheça o efeito transbordamento e busque avaliá-lo, estes estudos analisam os países de forma conjunta e com pouco grau de especificidade. Os únicos estudos que analisam os efeitos do QE sobre o Brasil são Barroso, Silva e Sales (2013) e Hara(2014). Barroso, Silva e Sales (2013) investigam se o QE exerceu alguma influência sobre os mercados emergentes. Os resultados são consistentes com a visão de que o $\mathrm{QE}$ teve um efeito positivo sobre o crescimento, mas também teve outros efeitos colaterais significativos na economia brasileira. Estes efeitos foram transmitidos principalmente através de influxos "excessivos" de capital que levaram à apreciação cambial, aumento dos preços no mercado de ações e a um boom no mercado de crédito. Hara(2014) busca avaliar, a partir de um modelo VAR, se o QE realizado pelos Estados Unidosprovocou uma apreciação da taxa de câmbio, um aumento dos yields dos títulos brasileiros e um aumento do índice Bovespa.

A contribuição deste estudo para a literatura é analisar se o efeito transbordamento do QE alterou o retorno dos ativos Ibovespa, a renda fixa, ataxa de câmbio, o riscopaís e os juros dos Estados Unidos. O trabalho é original ao elaborar um estudo de eventos e modelagem econométrica na finalidade de verificar os objetivos propostos.

\section{Dados e Metodologia}

Esta seção se encontra dividida em três subseções. A subseção 3.1 define os períodos em que ocorreram as intervenções do FED, via Quantitative Easing. A subseção 3.2 apresenta as variáveis utilizadas para identificar o impacto do quantitative easing sobre o Brasil. Por fim, a subseção 3.3 expõe o tratamento econométrico utilizado.

\subsection{Definição do Evento}

Conforme referido anteriormente, a adoção do QE foi dividida em três etapas: QE1 (02/01/2008 a01/07/2010), QE2 (02/07/2010 a03/01/2012) e QE3 (04/01/2012 a02/03/2015). Para identificar a causalidade do QE sobre as variáveis analisadas, consideram-se os seguintes eventos-chave: 
25 de novembro de 2008 (QE1): O FED anuncia que irá comprar mais de 100 bilhões de dólares em títulos emitidos por agências estatais (GSEs) e mais de 500 bilhões em títulos lastreados em hipotecas (Mortgage-Backed Security - MBS).

18 de março de 2009 (QE1): O FED anuncia que irá comprar 300 bilhões de dólares em títulos de longo prazo, 750 bilhões de dólares em MBS e 100 bilhões para compra de títulos das agências.

27 de agosto de 2010 (QE2): O FED irá fornecer mais liquidez ao sistema financeiro e reinvestirá o pagamento dos títulos comprados na rodada anterior.

3 de novembro de 2010 (QE2): O FED compra 600 bilhões de dólares em títulos de longo prazo do governo americano.

13 de setembro de 2012 (QE3): O FED comunica ao mercado que comprará 40 bilhões de dólares por mês em títulos lastreados em hipotecas (Mortgage-Backed Security - MBS).

12 de dezembro de 2012 (QE3): O FED faz o anúncio da compra não esterilizada (sem venda de títulos públicos) de 45 bilhões de dólares por mês em títulos de longo prazo.

A Figura 1 apresenta, de forma sucinta, os eventos a serem analisados. Além dos períodos de intervenção, definiu-se o período entre 03 de agosto de 2006 e 31 de junho de 2007 como o período de controle, denominado de QE0. ${ }^{2}$

Figura 1 - Intervenções realizadas pelo FED

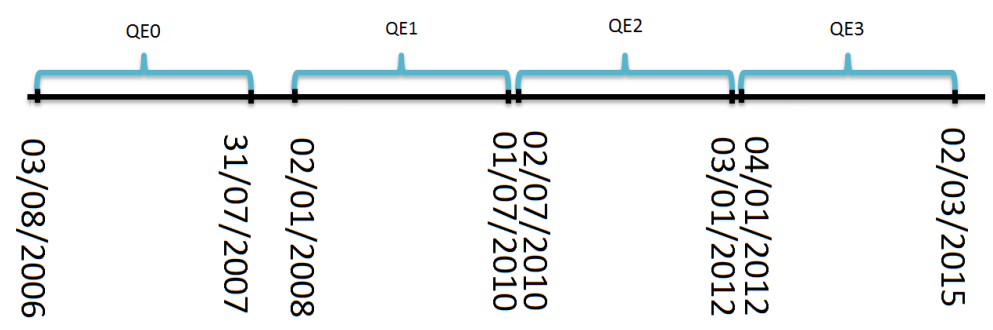

Fonte: Elaboração própria.

\subsection{Critério de Seleção}

Foram selecionados o Ibovespa, a taxa de câmbio, o riscopaís, os juros dos títulos do tesouro federal americano e o índice de renda fixa (IRF). Os juros dos Es-

$\overline{2}$ Os dados para o QE0 foram selecionados levando em consideração a ocorrência da crise. Assim, este período é considerado como não tendo interferência da crise nos ativos. 
tados Unidosforam obtidos no site do FED St. Louis. ${ }^{3}$ Todas as demais séries foram extraídas no software Economática.

\subsection{Tratamento Econométrico}

Para avaliar se o QE alterou a volatilidade dos ativos elabora-se um teste no qual verificar-se-á a existência de mudança estrutural para os ativos analisados, isto é, se os retornos e as variâncias dos ativos são diferentes ao longo dos períodos estudados.

Os retornos dos ativos, que estão disponibilizados em forma de pontuação, são obtidos por capitalização contínua:

$$
r_{t}=\ln \left(A_{t}\right)-\ln \left(A_{t-1}\right),
$$

em que r é o retorno do ativo específico; é o ativo em pontos no período t; e é o ativo em pontos no período $t-1 .{ }^{4}$

Em seguida, um modelo autoregressivo $\mathrm{AR}(p)$ é utilizado para estimar os parâmetros, conforme segue:

$$
R_{t}=\alpha_{0}+\sum_{p=1}^{n} \alpha_{p} R_{t-p}+\varepsilon_{t+1}
$$

em que é um choque aleatório, tal que $\varepsilon_{\mathrm{t}+1} \sim \mathrm{N}(0,1)$.

A média incondicional do modelo $\mathrm{AR}(p)$ encontra-se detalhadamente no Apêndice6.1. Esta é dada por:

$$
E\left(R_{t}\right)=\frac{\alpha_{0}}{\left(1-\sum_{p=1}^{n} \alpha_{p}\right.} .
$$

O modelo $\mathrm{ARCH}(p)$ ou o modelo $\operatorname{EGARCH}(p, q)$ é utilizado para modelar a variância incondicional. O modelo ARCH(p) é definido porEngle(1982) como:

$$
\sigma_{t}^{2}=\alpha_{0}+\sum_{p=1}^{n} \alpha_{p} a_{t-p}^{2} .
$$

3 https://research.stlouisfed.org/fred2/categories

4 O retorno acumulado da taxa de juros no período $n$ é definido como $r$ $1, t+n=\left(1+i_{t}\right)\left(1+i_{t+1}\right) \ldots\left(1+i_{t+n}\right)$. Por sua vez, o retorno é dado por $r_{n}$ $=\ln \left(\frac{r_{a, t+n}}{r_{a, t+n}-1}\right)$. 
O modelo EGARCH(1,1), proposto por Nelson (1991), é dado por:

$$
\ln \left(\sigma_{t}^{2}\right)=\gamma_{0} \frac{+\alpha_{1} \alpha_{t-1}+\gamma_{1}\left|\alpha_{t-1}\right|}{\sigma_{t-1}}+\beta_{1} \ln \left(\sigma_{t-1}^{2}\right) .
$$

A fórmula para variância incondicional do modelo $\mathrm{ARCH}(p)$ é apresentada no Apêndice6.2, enquanto que a fórmula para a variância incondicional do modelo $\operatorname{EGARCH}(p, q)$ é apresentada no Apêndice6.3. Desta forma, para o modelo $\mathrm{ARCH}(p)$ a variância incondicional é definida por:

$$
E\left(R_{t}\right)=\frac{\alpha_{0}}{\left(1-\sum_{p=1}^{n} \alpha_{p}\right)}
$$

Para o modelo $\operatorname{EGARCH}(p, q)$, a variância incondicional é dada por:

$$
E\left(R_{t}\right)=\frac{\gamma_{0}}{\left(1-\sum_{p=1}^{n} \beta_{p}\right)} .
$$

O teste DF-GLS foi utilizado para definir o número de defasagens ótimas dos modelos $\mathrm{AR}(p), \mathrm{ARCH}(p)$ ou $\operatorname{EGARCH}(p, q)$. DF-GLS 5 é um eficiente teste de raíz unitária e é similar ao teste Dicky-Fuller. No entanto, o teste DF-GLS apresenta melhor perfomance em amostras pequenas e quando média ou tendência desconhecida está presente nos dados (ELLIOTT;ROTHENBERG; STOCK, 1992).

Uma vez obtidas as médias incondicionais dos retornos e das variâncias para cada período, busca-se verificar se a política de QE alterou o retorno dos ativos, bem como sua volatilidade. Para avaliar a significância estatística dos retornos, emprega-se o teste $t$. Segundo Montgomery, Runger e Calado (2003), quando as médias e variâncias de duas populações forem desconhecidas e diferentes, o teste $t^{6}$ é dado por:

$$
t=\frac{x_{b}-x_{a}}{\sqrt{\frac{s_{b}^{2}}{n_{b}}-\frac{s_{a}^{2}}{n_{a}}}}
$$

sendo $X$ o retorno do ativo; $S$ a variância incondicional; e $n$ o número de observações.

$5 \quad$ O teste DF-GLS estima o número de defasagens ótimas por intermédio de três critérios, a saber: metodologia do teste $t$ sequencial Ng-Perron (1995); critério de informação Baynesiano de Schwartz (SBIC); e critério de informação modificado de Akaike (MAIC).

6

Os graus de liberdade para o teste $t$ são dados por: $\frac{\frac{s_{1}^{2}+s_{2}^{2}}{\left.\frac{1}{1}\right)^{2}}}{\frac{\left(s_{2}^{2}\right.}{1+1}+\frac{n_{2}^{2}}{n_{2}+1}}-2$. 
Para verificar a ocorrência de mudanças na volatilidade das séries devido às interferências do FED, realiza-se o teste de mudança de variância. Segundo Montgomery, Runger e Calado(2003), quando duas amostras são diferentes, as diferenças de variância podem ser estimadas pelo teste $F^{7}$ definido por:

$$
F=\frac{s_{2}^{2}}{s_{1}^{1}}
$$

\section{Resultados}

Uma vez relatadaa metodologia utilizada, apresentam-se os resultados alcançados. A Tabela 1 apresenta os modelos indicados pelo critério de informação Baynesiano Schwartz (BSIC). ${ }^{8}$ No QE0 todas as séries são estimadas por modelos $A R(1)$, exceto o Ibovespa que será estimado por um modelo AR(13). No QE1, todos as séries deverãoser estimadas por modelos autoregressivos com 4 ou mais defasagens. No QE2 todas as séries são estimadas por modelos AR(1), exceto a taxa de juros dos Estados Unidosque deverá ser estimada por um modelo AR(2) e o Ibovespa por um AR(5). Por fim, no QE3 todas as séries são estimadas por modelos AR(1), exceto a taxa de juros dos Estados Unidosque deverá estimada por um modelo AR(4).

Tabela 1- Modelo selecionado pelo DF-GLS

\begin{tabular}{c|ccc}
\hline Intervenção & Série & Modelo AR & Volatilidade \\
\hline \multirow{2}{*}{ QE0 } & Juros EUA & $\mathrm{AR}(1)$ & $\mathrm{ARCH}(5)$ \\
& Ibovespa & $\mathrm{AR}(13)$ & $\mathrm{EGARCH}(6,6)$ \\
& Risco-país & $\mathrm{AR}(1)$ & $\mathrm{ARCH}(2)$ \\
& Câmbio & $\mathrm{AR}(1)$ & $\mathrm{ARCH}(3)$ \\
& Renda Fixa & $\mathrm{AR}(1)$ & $\mathrm{ARCH}(5)$ \\
\hline \multirow{5}{*}{ QE1 } & Juros EUA & $\mathrm{AR}(5)$ & $\mathrm{EGARCH}(5,5)$ \\
& Ibovespa & $\mathrm{AR}(5)$ & $\mathrm{EGARCH}(5,5)$ \\
& Risco-país & $\mathrm{AR}(4)$ & $\mathrm{ARCH}(4)$ \\
& Câmbio & $\mathrm{AR}(9)$ & $\mathrm{ARCH}(4)$ \\
& Renda Fixa & $\mathrm{AR}(5)$ & $\mathrm{ARCH}(5)$ \\
\hline \multirow{2}{*}{ QE2 } & Juros EUA & $\mathrm{AR}(2)$ & $\mathrm{ARCH}(6)$ \\
& Ibovespa & $\mathrm{AR}(5)$ & $\mathrm{ARCH}(5)$ \\
\hline
\end{tabular}

7 Os graus de liberdade para o teste $F$ são dados por $\left.\left(\eta_{2}-1\right) \quad \eta_{2}-1\right)$ observações no mumerador; e $\left.\left(\eta_{1}-1\right) r_{1}-1\right)$ observações no denominador.

8 O critério de informação Baynesiano Schwartz foi o que melhor se adaptou aos modelos autorregressivos, em termos de operacionalidade, fornecendo os números de defasagens ótimas. 
conclusão.

\begin{tabular}{c|ccc}
\hline Intervenção & Série & Modelo AR & Volatilidade \\
\hline \multirow{2}{*}{ QE3 } & Risco-país & $\mathrm{AR}(1)$ & $\mathrm{ARCH}(2)$ \\
& Câmbio & $\mathrm{AR}(1)$ & $\mathrm{ARCH}(4)$ \\
& Renda Fixa & $\mathrm{AR}(1)$ & $\mathrm{ARCH}(3)$ \\
\hline \multirow{2}{*}{} & Juros EUA & $\mathrm{AR}(4)$ & $\mathrm{ARCH}(4)$ \\
& Ibovespa & $\mathrm{AR}(1)$ & $\mathrm{ARCH}(3)$ \\
& Risco-país & $\mathrm{AR}(1)$ & $\mathrm{ARCH}(2)$ \\
& Câmbio & $\mathrm{AR}(1)$ & $\mathrm{ARCH}(2)$ \\
& Renda Fixa & $\mathrm{AR}(1)$ & $\mathrm{ARCH}(5)$ \\
\hline
\end{tabular}

Fonte: Elaboração própria.

O Apêndice6.4 apresenta a Tabela 6, na qual se encontram os resultados obtidos para os coeficientes estimados dos modelos AR(p). Ao analisar a Tabela 6, observa-se que, em sua maioria, os modelos estimados demonstram ser globalmente significativos, ao nível de significância de 5\%, para todas as variáreis modeladas e para todos os segmentos de dados de séries temporais modelados.

Os resultados encontrados para as médias e as variâncias incondicionais são apresentados na Tabela 2, a partir da qual foram retiradas algumas conclusões, apresentadas nos parágrafos abaixo.

Tabela 2 -Média incondicional do modelo $\operatorname{AR}(p)$ e variância incondicional dos modelos $\operatorname{ARCH}(p)$ ou $\operatorname{EGARCH}(p, q)$

\begin{tabular}{c|ccc}
\hline Intervenção & Indicador & Variância & Média \\
\hline QE0 & Ibovespa & 1,021 & 0,00 \\
& Risco-país & $5,11 \mathrm{E}-04$ & $2,42 \mathrm{E}-06$ \\
& Câmbio & $2,07 \mathrm{E}-05$ & $-7.51 \mathrm{E}-05$ \\
& Juros EUA & $2,45 \mathrm{E}-08$ & $-4.13 \mathrm{E}-06$ \\
& Renda Fixa & $4,70 \mathrm{E}-07$ & $6.51 \mathrm{E}-01$ \\
\hline \multirow{2}{*}{ QE1 } & Ibovespa & 1,012 & $0,00 \mathrm{E}+00$ \\
& Risco-país & 0,0031 & $1,24 \mathrm{E}-04$ \\
& Câmbio & 0,0001 & $1,44 \mathrm{E}-05$ \\
& Juros EUA & 1,000 & $2.92 \mathrm{E}-08$ \\
& Renda Fixa & $2,21 \mathrm{E}-06$ & $2,39 \mathrm{E}+06$ \\
\hline \multirow{2}{*}{ QE2 } & Ibovespa & 0,0002 & $-5.60 \mathrm{E}+02$ \\
& Risco-país & 0,0015 & $9.15 \mathrm{E}-05$ \\
\hline
\end{tabular}




\begin{tabular}{c|ccc}
\hline Intervenção & Indicador & Variância & Média \\
\hline \multirow{2}{*}{ QE3 } & Câmbio & $4,49 \mathrm{E}-05$ & $-6.35 \mathrm{E}-05$ \\
& Juros EUA & $4,72 \mathrm{E}-09$ & $-4.56 \mathrm{E}+01$ \\
& Renda Fixa & $1,02 \mathrm{E}-06$ & $-1,78 \mathrm{E}-06$ \\
\hline \multirow{2}{*}{} & Ibovespa & 0,0002 & 0,0101 \\
& Risco-país & 0,0005 & $-6,12 \mathrm{E}-06$ \\
& Câmbio & $3,84 \mathrm{E}-05$ & 0,0001 \\
& Juros EUA & $1,87 \mathrm{E}-29$ & $-9.01 \mathrm{E}+00$ \\
& Renda Fixa & $2,34 \mathrm{E}-06$ & $7.94 \mathrm{E}-06$ \\
\hline
\end{tabular}

Fonte: Elaboração própria.

Com relação à variável Ibovespa, os retornos médios incondicionais permaneceram inalterados no período QE0 em relação ao período QE1. No entanto, no período QE2 o retorno sofreu uma forte queda e alcançou o valor de -5.600 e, finalmente, de0,0101 em QE3. Nota-se, a partir desses resultados, que os retornos médios do índice Ibovespa não se mantiveram inalterados aos processos de instabilidades que transcorreram nos mercados financeiros das economias mundiais, durante o período de análise dos dados.

O período QE0 (03/08/2006 a31/07/207) se caracteriza pelo período antes da crise, e pode-se observar que o retorno médio estimado para o Ibovespa no período permanece inalterado, mostrando assim que a crise não alterou a volatilidade do ativo. O período QE1 écaracterizado pelas intervenções do FED, por meio de compras de títulos GSEs, títulos MBS e títulos de longo prazo. Esse processo de compra de títulos pelo governo americano aumentou a liquidez na economia internacional, impactando positivamente na liquidez do índice Ibovespa, e permitiu que o retorno do ativo não sofresse uma acentuada queda. O período QE2, considerado como a segunda etapa da intervenção do FED no mercado financeiro americano, caracterizou-se por uma continuidade e intensificação dos volumes de compra dos mesmos títulos especificados em QE1. No entanto, observa-se que para esse período o retorno médio do Ibovespa tornou-se negativo, demonstrandoque a liquidez imposta na economia americana (e com consequentes impactos nas economias internacionais) não causou significativos impactos positivo no mercado dos títulos da Bovespa-BMF, ao menos, não sendo suficiente para compensar os efeitos da pré-crise das economias da União Europeia. ${ }^{9}$ Finalmente, no período

9 Em 2010 iniciou a crise na União Europeia, que persiste até o momento, causada pela dificuldade de alguns países europeus em pagar as suas dívidas, devido à falta de coordenação política da União Europeia para resolver as questões de endividamento público das nações do bloco. Cinco dos países da região - Grécia, Portugal, Irlanda, Itália e Espanha - não vêm conseguindo gerar crescimento econômico suficiente para honrar os compromissos firmados junto aos seus credores 
QE3, em que o FED continuou implementado compras de títulos lastreados em hipotecas, MBS e títulos de longo prazo, observa-se que o retorno médio do Ibovespa voltou a subir, possivelmente influenciado pela liquidez imposta pelo mercado financeiro dos Estados Unidos, com impacto positivo no retorno médio do Ibovespa.

De forma similar ao comportamento do Ibovespa, observa-se na Tabela 2 que os retornos médios incondicionais do Cambio evoluíram de -0,0000751, em QE0, para 0,0000144, em QE1, reduziram-separa 0.0000635 em QE2 e novamente se elevaram para $0,0001 \mathrm{em} \mathrm{QE} 3$. Os retornos médios incondicionais da renda fixa evoluíram de 0.651, em QE0, para 2.39 E+06, em QE1. Já no QE2, o ativo teve uma redução do seu retorno e este alcançou o valor de -0,00000178, enquanto no QE3, o retorno do ativo teve um aumento e alcançouo valor de 0,00000794. Finalmente, observa-se que as médias incondicionais do Risco-País evoluíram de 0,00000242 em QE0, para 0,000124 em QE1.No QE2, a média incondicional teve uma queda e alcançouo valor de 0,0000915 eno QE3 novamente o ativo teveuma queda no seu retorno e assumiu o valor de -0,00000612. Nota-se que o comportamento dessas variáveis recebe efeitos similares aos comentados anteriormente para o Ibovespa, com poucas exceções e com efeitos com intensidades menores, também subtendidos como sendo devidos aos impactos da política monetária não convencional americana.

De maneira geral, pode-se dizer que a política de compra de ativos financeiros lastreados nas instituições financeiras dos Estados Unidos, utilizada pelo FED com o objetivo de aumentar a liquidez na economia americana, provocou também efeito contágio no mercado financeiro brasileiro e alterou o retorno das variáveis analisadas neste estudo.

Contudo, observando-se a Tabela 2, constata-se que a variável Juros EUA sofre uma longa oscilação ao longo do período analisado, evoluindo a sua média de um valor -4.13 E-06 em QE0, para 2.92 E-08 em QE1, para -0,456 em QE2 e -9,0103 em QE3 (deve-se observar que estes valores estão representados na forma logaritmo, portanto, quando eles evoluem para - $\infty$, o valor em escala linear evolui para zero). Efeito similar ocorre com a variância incondicional dessa variável, conforme se observa na Tabela 2. Estes resultados induzem que as taxas de juros americana evoluíram para zero e com oscilações nulas.

Ademais, observa-se também na Tabela 2 que os resultados dos modelos autoregressivos heteroscedásticos especificados na Tabela 1, para cada período de séries, mostram que para a variável Ibovespa, a variância incondicional tem pouca

ao longo das últimas décadas. O risco de inadimplência é real e tem consequências de longo alcance, que se estenderam além das fronteiras da zona do euro. Conforme o presidente do Banco da Inglaterra, Mervyn King, em outubro de 2011 afirmou, "A crise da dívida europeia é a crise financeira mais séria desde os anos 1930, se não a mais séria da história”. A crise americana subprimenos Estados Unidos, entre 2008 e 2009, expôs as políticas fiscais insustentáveis dos países na Europa e no mundo (HAIDAR, 2012) 
variação ao longo dos períodos analisados. A variância incondicional da variável Cambiosofre grandes oscilações ao longo dos períodos. A variância incondicional da Renda Fixa permanece relativamente estável ao longo dos períodos. Finalmente, as variâncias incondicionais do Risco-País e dos Juros EUA apresentam grandes oscilações. De uma forma geral, nota-se a partir desses resultados que as políticas de compra de ativos financeiros utilizadas pelo FED, com o objetivo de impor liquidez na economia americana, provocaramtambém efeito contágio, alterando a volatilidade do mercado financeiro brasileiro.

\subsection{Testando a Significância Estatística dos Parâmetros}

Para avaliar se o QE altera os retornos dos ativos, avaliado através da média incondicional em cada período, utiliza-se o teste estatístico $t$ de student, conforme a Tabela 3. Como este teste verifica se os retornos são diferentes em cada período, deve ser interpretado como bicaudal.

A primeira coluna da Tabela 3 testa a hipótese de que as séries de retornos analisados no QE1 são estatisticamente diferentes dos retornos observados no QE0. Os resultados encontrados indicam que apenas o retorno da rendafixa é estatisticamente superior no QE1 ao retorno observado no QE0, para um nível de significância de $1 \%{ }^{10}$ Esse resultado indica um possível vazamento de recursos do QE para este ativo. Como o retorno alterou-se de forma positiva, é esperado que investidores externos tenham aplicado recursos em papéis brasileiros.

Tabela 3 - Valor encontrado para o teste $t$ de mudança de média incondicional

\begin{tabular}{c|ccc}
\hline Indicador & QE 1 - O & QE 2 - 1 & QE 3 - 2 \\
\hline Ibovespa & 0.02 & $-1.68 \mathrm{E}+14^{*}$ & $7.54 \mathrm{E}+14^{*}$ \\
& $(0.98)$ & $(0.00)$ & $(0.00)$ \\
Riscopaís & 0.05 & $-0.013^{*}$ & -0.055 \\
& $(0.96)$ & $(0.00)$ & $(0.95)$ \\
Câmbio & 0.19 & -0.157 & 0.233 \\
& $(0.84)$ & $(0.99)$ & $(0.81)$ \\
Juros EUA & 0.00 & $-1.37 \mathrm{E}+14^{*}$ & $1.24 \mathrm{E}+14^{*}$ \\
Renda Fixa & $(1.00)$ & $(0.00)$ & $(0.00)$ \\
& $39 \mathrm{E}+09^{*}$ & $-3.64 \mathrm{E}+14^{*}$ & 0.156 \\
& $(.000)$ & $(0.00)$ & $(0.87)$ \\
\hline
\end{tabular}

Fonte: Elaboração própria.

10 O símbolo de asteriscos (*) indica que a variável é estatisticamente significante a nível de 1\% para o teste de diferença de média incondicional. Os números em parênteses representam o p-valor para o referido teste em cada variável 
A segunda coluna da Tabela 3 testa a hipótese de que o retorno dos indicadores considerados no QE2 é estatisticamente diferente do observado no período QE1. Os resultados encontrados indicam que o retorno dos ativos Ibovespa, risco país, Juros EUA e renda fixa são estatisticamente significantes. Assim, estes ativos tiveram seus retornos alterados devido à política do $\mathrm{QE}$ adotado pelo governo norte-americano. Como destaca Morgan (2011), parte dos recursos do QE2 vazou em forma de capital privado. A aplicação em ativos brasileiros pode ter sido um dos destinos destes recursos.

A terceira coluna da Tabela 3 indica que os retornos do Ibovespa e dos juros dos Estados Unidos no período QE3 são superiores e estatisticamente significantes ao período QE2. Neste período, o governo brasileiro adotou medidas para evitar a valorização da moeda e consequentemete o recurso do QE3 vazou para os ativos Ibovespa. Por sua vez, a indicação do fim dos estímulos de liquidez dadospelo FED podem ter ocasionado uma maior procura pelo ativo Juros EUA e isto gerou um aumento do retorno deste ativo. Portanto, conclui-se que, em menor ou maior grau, a política de intervenção do FED e seu possível vazamento de capital alteraram os retornos dos ativos.

A Tabela 4 apresenta o resultado para o teste de mudança de variância incondicional causado pela política de intervenção do FED.

Tabela 4 - Valor encontrado para o teste $F$ de mudança de variância incondicional

\begin{tabular}{c|ccc}
\hline Indicador & QE 1 - 0 & QE 2 - 1 & QE 3 - 2 \\
\hline Ibovespa & 0.99 & $2.05 \mathrm{E}-04$ & 0.96 \\
& $(0.54)$ & $(1.00)$ & $(0.71)$ \\
Riscopaís & $6.26^{*}$ & 0.45 & 0.35 \\
& $(0.00)$ & $(1.00)$ & $(1.00)$ \\
Câmbio & $7.13^{*}$ & 0.30 & 0.85 \\
& $(0.00)$ & $(1.00)$ & $(0.98)$ \\
Juros EUA & $4.09 \mathrm{E}+07^{*}$ & $4.72 \mathrm{E}-09$ & $3.97 \mathrm{E}-21$ \\
& $(0.00)$ & $(1.00)$ & $(1.00)$ \\
Renda Fixa & $4.71^{*}$ & 0.46 & $2.28^{*}$ \\
& $(0.00)$ & $(1.00)$ & $(0.00)$ \\
\hline
\end{tabular}

Fonte: Elaboração própria.

Ao analisar a primeira coluna da Tabela 4, observa-se que a política de QE alterou a variância inconcional dos ativos Riscopaís, Câmbio, Juros EUA e Renda Fixa no QE1, em relação ao QE0. A explicação para esta ocorrência é que a política adotada pelo governo americano de compras de títulos públicos e privados 
aumentou a incerteza do mercado. Assim, o comportamento dos agentes econômicos se tornouheterogêneo e houveuma grande dispersão entre a compra e venda dos ativos, aumentando assim a sua volatilidade.

A segunda coluna da Tabela 4 testa a hipótese de que a variância incondicional dos ativos analisados éestatisticamente diferente do observado no período QE1. Os resultados mostram que nenhum dos ativos teve sua variância incondicional alterada. A explicação para este fato é que os agentes aprenderam os efeitos da política com a adoção do QE1 e não mudaram seu comportamento.

Por fim, a terceira coluna da Tabela 4 indica que apenas a variância incondional do ativo renda fixa é alterado no QE3 em relação ao QE2. A possível explicação para esta ocorrência é que, no período analisado, as taxas de juros brasileiras estavam em um patamar baixo e os agentes começaram a questionar se o Banco Central Brasileiro seria capaz de manter esta taxa reduzida por maior período de tempo. Não acreditando que a taxa de juros brasileira iria permanecer baixa por mais tempo, grande parte dos aplicadores transferiram seus recursos para o mercado de renda fixa.

\subsection{Quebra Estrutural}

Levando em consideração o fato que os testes de raiz unitária podem produzir falsas evidências de nãoestacionariedade quando existem quebras de exibição de séries temporais estruturais, buscou-se resolver este problema adotando o teste Zandrews proposto por Zivot eAndrews (2002) e os testes clemao2 e clemio2 sugeridos por Clemente, Montanes e Reyes (1998). Estes testes têm a finalidade de testar a hipótese de raiz unitária, tendo em conta a possibilidade de quebras estruturais nos dados de nosso estudo. Assim, estes testes foram aplicados primeiro para verificar a presença de raiz unitária na presença de quebras, e segundo para identificar a presença de quebras. Esse processo foi realizado mapeando cada série em toda sua amplitude, por meio de fixação do teste em alguma parte da série.

O teste Zandrews permite uma única quebra estrutural no intercepto e/ou numa única tendência na série, determinado por uma pesquisa sobre possíveis grandes pontos de interrupção. Subsequentemente, o processo conduz a um teste de raiz unidade subordinada à série, semelhante ao teste de Dickey-Fuller aumentado, incluindo as rupturas ótimas estimadas. Para controlar o problema de encontrar apenas uma quebra, o teste pode ser aplicado em uma parte da série e se pode descobrir outros pontos de quebra, mapeando, assim, todo o comportamento da série histórica. Semelhante ao método implementado em DF-GLS, o teste Zandrews proporciona três diferentes métodos para a selecção de comprimento fundamental ótimo, baseando-se no teste $t$ sequencial de Ng-Perron (1995): o cri- 
tério de informação Bayesiano Schwarz (BIC), o critério de informação Akaike e ocritério de informaçãoAIC.

O teste de quebra estrutural proposto por Zivot eAndrews (2002) é utilizado para identificar se o QE provocou uma quebra estrutural nas séries analisadas. Ele representa uma alternativa ao teste $t$, realizado na seção anterior. Zivot eAndrews (2002) propuseram três testes:

1) Identifica uma mudança de nível no modelo estimado para os retornos:

$$
\Delta y_{t}=c+\alpha y_{t-1}+\beta t+\gamma D U_{t}+\sum_{j=1}^{k} d_{j} \Delta y_{t-j}+\varepsilon_{t}
$$

2) Verifica se ocorreu uma mudança na inclinação do modelo estimado para os retornos:

$$
\Delta y_{t}=c+\alpha y_{t-1}+\beta t+\theta D T_{t}+\sum_{j=1}^{k} d_{j} \Delta y_{t-j}+\varepsilon_{t}
$$

3) Analisa se houve uma mudança no nível e uma mudança na inclinação do modelo estimado para os retornos:

$$
\Delta y_{t}=c+\alpha y_{t-1}+\beta t+\theta D U_{t}+\sum_{j=1}^{k} d_{j} \Delta y_{t-j}+\varepsilon_{t}
$$

Os resultados encontrados para o teste de quebra estrutural de Zivot eAndrews (2002), Apêndice6.5, indicam a ocorrência de três quebras no Ibovespa: a primeira quebra ocorreu no dia 21 de novembro de 2008, 4 dias antes da primeira etapa do QE1; a segunda quebra ocorreu no dia 09 de março de 2009, nove dias antes do FED anunciar a segunda etapa do QE1 e a terceira quebra ocorreu no dia 20 de março de 2009, dois dias após o FED anunciar a segunda etapa do QE1.

O teste Zivot eAndrews (2002) indica a presença de quebra estrutural na variável câmbio no dia 07 de dezembro de 2008, doze dias após o anúncio da primeira etapa do QE1. O ativo riscopaís sofreu uma quebra estrutural no dia 21 de novembro de 2008, quatro dias antes do anúncio da primeira etapa do QE1. A variável renda fixa sofreu uma quebra estrutural no dia 23 de março de 2009, cinco dias depois do anúncio da primeira etapa do QE1. Por fim, a taxa de juros dos Estados Unidossofreu uma quebra estrutural no dia 17 de março de 2009, um dia antes do anúncio da primeira etapa do QE1. Portanto, os resultados alcançados para o teste de quebra estrutural de Zivot eAndrews (2002) mostram, em sua maioria, que os agentes anteciparam as notícas de implantação do QE realizada pelo FED no QE1. No entanto, como ocorrido no teste de mudança de variância, o teste não conseguiu captar quebras no $\mathrm{QE} 2$ e no $\mathrm{QE} 3$, o quenos faz acreditar que os agentes econômicos aprenderam e não mudaram seu comportamento perante a política do quantitative easing. 
Clemente, Montanes e Reyes (1998) propuseram um teste que identifica duas quebras estruturais na série de dados. De acordo com os autores, os testes de raízes unitárias propostos por eles envolvem dois eventos alternativos dentro da série tempo: o modelo de "outlier aditivo" (CLEMAO), que captura uma mudança repentina na série, e o modelo de "outlier inovação" (CLEMIO), que permite uma mudança gradual na média da série. Por conveniência, foi testadaa presença de raiz unitária permitindo a existência de duas quebras estruturais. Estes testes também podem ser aplicadosem uma parte da série de tempo e se podem descobrir os outros pontos de quebra, mapeando, assim, todo o comportamento da série histórica.

O teste para a presença de outliers aditivos (AO) identifica saltos persistentes nos retornos. Este teste é realizado conforme segue:

Inicialmente estima-se a seguinte regressão:

$$
y_{t}=\mu+\sigma_{1} D U_{1 t}+\sigma_{2} D U_{2 t}+\tilde{y}
$$

em que $D U_{m t}=1$ para $t>T_{b m}$ e 0 , caso contrário, para $m=1,2 . T_{b 1}$ e $T_{b 2}$ são os pontos de quebra a serem localizados. Em um segundo momento, o resíduo, , é regredido contra seus valores defasados e um grupo de variáveis binárias:

$\tilde{y}=\sum_{i=1}^{k} w_{1 i} D T_{b 1, t-1}+\sum_{i=1}^{k} w_{2 i} D T_{b 2, t-1}+\alpha \tilde{y}_{t-1}+\sum_{i=1}^{k} \theta_{i} \Delta \tilde{y}_{t-1}+\varepsilon_{t}(14)$

em que $D t_{b m, t}=1$ para $t=T_{b m}+1$;e 0 , caso contrário, para $m=1,2$.

O teste para a presença de outlier inovacional (IO) identifica mudanças contínuas de nível, que se repetem e criam efeitos persistentes. Este teste é realizado através da estimação do seguinte modelo:

$\tilde{y}_{t}=\mu+\sigma_{1} D U_{1 t}+\sigma_{12} D U_{2 t}+\emptyset_{1} D U_{b 1, t}+\emptyset_{2} D U_{b 2, t}+\alpha_{1} \tilde{y}_{t-1}+\sum_{i=1}^{K} \theta_{i} \Delta \tilde{y}_{t-1}+\varepsilon_{t}$

No que diz respeito aos resultados dos testes (outliers aditivos e outlier inovacional) observa-se que o Ibovespa e os Juros EUA apresentaram mudanças contínuas de nível e saltos persistentes no QE1. No QE2, apenas o Risco-país apresentou mudanças contínuas de nível e saltos persistentes devido à realização do quantitative easing. Por fim, no QE3 não ocorreram quebras nas séries analisadas.

\subsection{A Política do Quantitative Easing reduz a Volatilidade dos Ativos?}

Os modelos $\mathrm{AR}(p)$ estimados mostraram que o $\mathrm{QE}$ gerou mudanças estruturais no retorno dos ativos estudados. O próximo teste busca verificar se o início/ fim do QE reduziu a volatilidade dos ativos analisados. Os períodos utilizados para 
a estimação são diferentes dos adotados até o momento. Para o início do QE1, considera-se como base o período entre 01 fevereiro de 2010 a 30 de abril de 2010 e como grupo de tratamento o período entre 01 de maio de 2010 e 31 maio de 2010. Por sua vez, para o QE2 o período entre 30 Julho de 2010 e 31 de outubro de 2010 é utilizado como grupo de controle e o período entre 01 de novembro de 2010 e 16 de Junho de 2011 é definido como o grupo de tratamento. Por fim, testa-se a hipótese de que o início do QE3 reduziu a volatilidade. Para este teste, utiliza-se como base o período entre 20 de Julho de 2011 e 12 de setembro de 2013 e como grupo de tratamento o período entre 13 de setembro de 2013 e 10 de setembro de 2014 .

A forma funcional do retorno do ativo em cada período analisado é dada, segundoTan eKohli(2011), por:

$$
R_{t+1}=\left[\alpha+\alpha_{\pi} I(\pi)\right]+\left[\beta R_{t}+\beta_{\pi} R_{t}(\pi)\right]+\varepsilon_{t+1},
$$

no qual $\pi$ denota o período de tratamento que receberá a variável binária.

Os parâmetros são estimados por máxima-verossimulhança:

$$
\hat{\theta} \sim \theta, \frac{1}{T-1}\left[\sum_{t=1}^{T} \frac{\left(\partial l R_{t+1} \mid F_{t}\right)}{\partial \theta} \frac{\left(\partial l R_{t+1} \mid F_{t}\right)}{\partial \theta}\right]^{-1}
$$

Obtidos os parâmetros, a mudança da média incondicional em cada período é dada por:

$$
\Delta_{m}=\frac{\alpha+\alpha_{\pi}}{1-\beta-\beta_{\pi}}-\frac{\alpha}{1-\beta}
$$

Os resultados apresentados na Tabela 4 indicam que o fim do QE1 resultou em um aumento da volatilidade do Renda Fixa, enquanto que os outros ativos não tiveram seu retorno alterado. Uma possível explicação para esta ocorrência é que o fim do QE1 reduziu a liquidez da economia e a captação de recursos externos via títulos públicos se tornou mais elevada.

Os resultados obtidos para (17) indicam que o início do QE2 reduziu a volatilidade dos ativos e resultou em uma diminuição da volatilidade do índice Ibovespa. A explicação para este fato é que ao realizar o QE2, o FED sinalizou que iria manter a política de estímulo econômico e isto aumentou a confiança dos investidores.

Por fim, a realização do QE3 resultou em uma diminuição da volatilidade do câmbio e no aumento da volatilidade do riscopaís. O principal motivo desta ocorrência é que o QE3 sinalizou que a taxa de juros americana continuaria baixa por um maior período de tempo, assim a procura por títulos brasileiros aumentou 
e consequentemente elevou a volatilidade do riscopaís. Por sua vez, como os investidores irão manter seus ativos no Brasil e os investimentos brasileiros oferecem maior retorno, a procura por moeda estrangeira foi menor.

Tabela 4 - Valores estimados para o teste aplicado para verificar se o Quantitative Easing influenciou na volatilidade dos ativos

\begin{tabular}{|c|c|c|c|c|c|c|c|c|}
\hline \multicolumn{9}{|c|}{ Valor estimados para QE1 } \\
\hline $\begin{array}{l}\text { Parâ- } \\
\text { metro }\end{array}$ & \multicolumn{2}{|c|}{ IBOVESPA } & \multicolumn{2}{|l|}{ CÂMBIO } & \multicolumn{2}{|c|}{ RISCO-PAÍS } & \multicolumn{2}{|l|}{ IRF } \\
\hline beta & 0,0001 & 0,0019 & $-0,0013$ & 0,0012 & $-0,0032$ & 0,005 & $0.0003 * *$ & 0,0001 \\
\hline II & 0,1867 & 0,1573 & $-0,008$ & 0,1596 & $-0,04$ & 0,1577 & 0,0311 & 0,1244 \\
\hline $\mathrm{xt}-1$ & $-0,0044$ & 0,0036 & 0,0033 & 0,0025 & 0,0124 & 0,0101 & 0 & 0,0002 \\
\hline II xt-1 & $-0,3049$ & 0,2152 & 0,1651 & 0,2215 & 0,2002 & 0,2188 & $0.5476 * *$ & 0,2325 \\
\hline $\begin{array}{l}\text { Delta } \\
\mathrm{m}\end{array}$ & 0,142572 & & $-0,00988$ & & $-0,05162$ & & 0,069108 & \\
\hline \multicolumn{9}{|c|}{ Valor estimados para QE2 } \\
\hline $\begin{array}{l}\text { Parâ- } \\
\text { metro }\end{array}$ & \multicolumn{2}{|c|}{ IBOVESPA } & \multicolumn{2}{|l|}{ CÂMBIO } & \multicolumn{2}{|c|}{ RISCO-PAÍS } & \multicolumn{2}{|l|}{ IRF } \\
\hline beta & 0,0029 & 0,0017 & $-0,0005$ & 0,0007 & $-0,0063$ & 0,005 & 0,0003 & 0,1288 \\
\hline II & $(0.137)^{*}$ & 0,171 & 0,0107 & 0,1533 & 0,0752 & 0,1688 & 0,0516 & 123,2431 \\
\hline $\mathrm{xt}-1$ & $-0,0037$ & 0,0019 & 0,0002 & 0,0008 & 0,0066 & 0,0056 & 0,1596 & 0,1473 \\
\hline II xt-1 & 0,0854 & 0,1894 & 0,1029 & 0,1722 & $-0,2379$ & 0,1857 & 0,5156 & 123,2431 \\
\hline $\begin{array}{l}\text { Delta } \\
\mathrm{m}\end{array}$ & $-0,14892$ & & 0,011873 & & 0,062299 & & 0,159434 & \\
\hline \multicolumn{9}{|c|}{ Valor estimados para QE3 } \\
\hline $\begin{array}{l}\text { Parâ- } \\
\text { metro }\end{array}$ & \multicolumn{2}{|c|}{ IBOVESPA } & \multicolumn{2}{|l|}{ CÂMBIO } & \multicolumn{2}{|c|}{ RISCO-PAÍS } & IRF & \\
\hline beta & $-0,0002$ & 0,0006 & $0.0005^{*}$ & 0,0003 & $-0,0005$ & 0,0015 & $0.0004^{* *}$ & 0,0001 \\
\hline II & $-0,0269$ & 0,0415 & $0.158^{*}$ & 0,0409 & $(0.0915)^{*}$ & 0,044 & 0,0626 & 0,043 \\
\hline $\mathrm{xt}-1$ & 0,0003 & 0,0011 & $-0,0003$ & 0,0005 & 0,0012 & 0,002 & 0 & 0,0001 \\
\hline II xt-1 & $-0,0663$ & 0,0754 & $(0.1636)^{*}$ & 0,0739 & $0.2214^{* *}$ & 0,0709 & $-0,0255$ & 0,0712 \\
\hline $\begin{array}{l}\text { Delta } \\
\mathrm{m}\end{array}$ & $-0,02522$ & & 0,13568 & & $-0,11784$ & & 0,061033 & \\
\hline
\end{tabular}

Fonte: Elaboração própria 


\section{Considerações Finais}

Diante da crise financeira de 2008, os bancos centrais de vários países reduziram as taxas de juros de curto prazo para valores próximos de zero. No entanto, esta política não foi capaz de garantir a liquidez da economia e de sustentar a atividade econômica. Assim, os bancos centrais de vários países passaram a utilizar a compra de ativos privados como instrumento de política monetária (quantitative easing).

Embora o objetivo do QE fosse aumentar a base monetária da economia americana em resposta aos desencadeamentos da crise financeira e garantir o bom funcionamento da economia interna, seu efeito transbordamento foi sentido nos países emergentes. Diante desta situação, o presente estudo avaliou se o QE, adotado pelo FED, alterou a volatilidade do índice Ibovespa, câmbio, riscopaís, Juros dos Estados Unidose índice de renda fixa.

Os resultados encontrados indicam que o ativo renda fixa, na primeira fase de intervenções do FED, QE1, apresentou um retorno superior ao observado no período pré crise, denominado de QE0 neste estudo. A renda fixa, o Ibovespa, o risco país e o juros Estados Unidostiveram seus retornos alterados na segunda fase de intervenções. Por fim, na terceira fase do QE, o Ibovespa e os Juros EUA voltaram aapresentar um retorno superior. Portanto, a política de compra de títulos públicos adotada pelo Banco Central dos Estados Unidosteve seu efeito transbordamento para ativos brasileiros.

No que diz respeito aos resultados do teste de mudança de variância ocasionada pela política de intervenção do FED, pode-se verificar que o QE1 resultou em aumento da volatilidade de todos os ativos analisados, exceto o Ibovespa. Para as demais políticas do $\mathrm{QE}$, apenas o ativo renda fixa tem sua volatilidade afetadano QE3. Este resultado nos leva a acreditar que os agentes econômicos não sabiam quais os efeitos da política adotada pelo governo americano.Uma vez que esta foi realizada no QE1, os agentes aprenderam e não mudaram seu comportamento para as demais políticas. Por sua vez, o aumento da volatilidade do ativo renda fixa é explicado pela desconfiança diante do Banco Central Brasileiro em sua capacidade de manter a taxa de juros em patamar baixo e com isto, os agentes, buscando maior retorno e segurança, aplicaram seus recursos em maior volume no renda fixa e consequentemente a volatilidade deste ativo aumentou.

Os testes de quebra estrutural indicaram que o QE1 alterou o retorno de todas as séries financeiras analisadas com alguns dias de antecedência ao anúncio da nova política econômica do FED. Este resultado indica que os agentes que compõem o mercado financeiro antecederam e reagiram à política adotada pelo FED. Ademais, há evidências de que o fim do QE1 aumentou a volatilidade da renda fixa; o início do QE2 provocou uma redução da volatilidade dos ativos con- 
siderados, principalmente do Ibovespa e o QE3 aumentou a volatilidade do riscopaíse diminuiu a volatilidade do câmbio.

\section{Referências}

BARROSO, J. B. R.; SILVA, L. A. P.; SALES, A. S. Quantitative easing and related capital flows into Brazil: measuring its effects and transmission channels through a rigorous counterfactual evaluation. Brasília, DF: Banco Central do Brasil, 2013. (Working Paper, n. 313).

BAUER, M. D.; RUDEBUSCH, G. D. Monetary policy expectations at the zero lower bound. Journal of Money, Credit and Banking, v. 48, n. 7, p. 1439-1465, 2016.

BAUMEISTER, C.; BENATI, L.Unconventional monetary policy and the great recessionestimating the impact of a compression in the yield spread at the zero lower bound. Canada: Bank of Canada, 2010. (Working Paper, n. 2012-21).

BERNANKE, B. Monetary policy since the onset of the crisis. In: FEDERAL RESERVE BANK OF KANSAS CITY ECONOMIC SYMPOSIUM, 2012, Jackson Hole. Speech... Jackson Hole:Board Of Governors Of The Federal Reserve System, 2012.

. The economic outlook and monetary policy. In: ANNUAL ECONOMIC POLICY SYMPOSIUM, 2010, Kansas. Proceedings... Kansas: Federal Reserve Bank of Kansas City, 2010.

BREEDON, F.; CHADHA, J. S.; WATERS, A. The financial market impact of UK quantitative easing. Oxford Review of Economic Policy, v.28, n.4, p. 702-728, 2012.

BRESSER-PEREIRA, L. C. A crise financeira de 2008.Revista de Economia Política, v. 29, n. 1, p. 133-149, 2009.

CLEMENTE, J.; MONTANES, A.; REYES, M. Testing for a unit root in variables with a double change in the mean. Economics Letters, v. 59, n. 2, p. 175-182, 1998.

D’AMICO, S.; KING, T. Flow and stock effects of large-scale treasury purchases. Finance and Economics Discussion Series, n. 52, 2010.

ELLIOTT, G.; ROTHENBERG, T. J.; STOCK, J. H. Efficient tests for an autoregressive unit root. Cambridge, MA: National Bureau of Economic Research, 1992. (NBER Working Paper, n. 130).

ENGLE, R. F. Autoregressive conditional heteroscedasticity with estimates of the variance of united kingdom inflation. Econometrica: Journal of the Econometric Society, v. 50, n. 4, p. 987-1007, 1982.

FAWLEY, B. W.; NEELY, C. J. Four stories of quantitative easing. Federal Reserve Bank of St. Louis Review, v. 95, n. 1, p. 51-88, Jan./Feb. 2013,

FRATZSCHER, M.; DUCA, M.; STRAUB, R. On the international spillovers of US quantitative easing. Frankfurt am Main: European Central Bank, 2013. (Working Paper Series, n. 1557). 
GAGNON, J. et al. The financial market effects of the Federal Reserve's large-scale asset purchases. International Journal of Central Banking, v. 7, n.1, p. 3-43, 2011.

GAGNON, J. R. M. R. J.; SACK, B. The financial market effects of the Federal Reserve's large-scale asset purchases. International Journal of Central Banking, v. 7, n.10, p. 3-43, 2011.

GLICK, R.; LEDUC, S. Central bank announcements of asset purchases and the impact on global financial and commodity markets. Journal of International Money and Finance, v. 31, n. 8, p. 2078-2101, 2012.

HAIDAR, J. I. Sovereign credit risk in the euro zone. World Economics, v. 13, n. 1, p. 1-15, 2012.

HAMILTON, J. D.; WU, J. C. The effectiveness of alternative monetary policy tools in a zero lower bound environment. Journal of Money, Credit and Banking, v. 44, n. 1, p. 3-46, 2012.

HARA, K. Impacto das políticas monetária não-convencional dos EUA nas variáveis financeiras do brasil pós crise de 2008. 2014. 74 f. Trabalho de Conclusão de Curso (Graduação em Ciências Econômicas) - Universidade Federal de Santa Catarina, Florianópolis, 2014.

HAUSMAN, J.; WONGSWAN, J. Global asset prices and fomc announcements. Journal of International Money and Finance, v. 30, n. 3, p. 547-571, 2011.

HOSONO, K. The transmission mechanism of monetary policy in japan: evidence from banks' balance sheets. Journal of the Japanese and International Economies, v. 20, n. 3, p. 380-405, 2006.

JOYCE, M. A.; MCLAREN, N.; YOUNG, C. Quantitative easing in the united kingdom: evidence from financial markets on qe1 and qe2. Oxford Review of Economic Policy, v. 28, n. 4, p. 671-701, 2012.

JOYCE, M. et al. Quantitative easing and unconventional monetary policy-an introduction. The Economic Journal, v. 122, n. 564, p. F271-F288, 2012.

JOYCE, M. A. S. et al. The financial market impact of quantitative easing in the United Kingdom. International Journal of Central Banking, v. 7, n. 3, p. 113-161, 2011.

KAPETANIOS, G. et al. Assessing the economy-wide effects of quantitative easing. The Economic Journal, v. 122, n. 564, p. F316-F347, 2012.

KASHYAP, A. K.; STEIN, J. C. What do a million observations on banks say about the transmission of monetary policy? American Economic Review, v. 90, n. 3, p. 407-428, Jun. 2000 .

KRISHNA MURTHY, A.; VISSING-JORGENSEN, A. The effects of quantitative easing on interest rates: channels and implications for policy. Cambridge: National Bureau of Economic Research, 2011. (Working Paper, n. 17555).

LENZA, M.; PILL, H.; REICHLIN, L. Monetary policy in exceptional times.Economic Policy, v. 25, n. 62, p. 295-339, 2010. 
LYONNET, V.; WERNER, R. Lessons from the bank of england on 'quantitative easing'and other 'unconventional'monetary policies. International Review of Financial Analysis, v. 25, p. 94-105, 2012.

MEANING, J.; ZHU,F. The impact of recent central bank asset purchase programmes. BIS Quarterly Review, Dec. 2011.

MONTGOMERY, D.C.; RUNGER, G. C.; CALADO,V. Estatística aplicada e probabilidade para engenheiros. Rio de Janeiro: Livros Técnicos e Científicos, 2003.

MORGAN, P. Impact of us quantitative easing policy on emerging Asia.Tokyo: Asian Development Bank Institute, Nov. 2011. (ADBI Working Paper Series, n. 321).

NEELY, C. The large scale asset purchases had large international effects. Missouri: Federal Reserve Bank of St. Louis,2011.

. The large-scale asset purchases had large international effects. Missouri: Federal Reserve Bank of St. Louis, 2010. (Working Paper, n. 2010-018(A)).

NELSON, D. B. Conditional heteroskedasticity in asset returns: a new approach. Econometrica: Journal of the Econometric Society, v. 59, n. 2, p. 347-370, 1991.

SCHENKELBERG, H.; WATZKA, S. Real effects of quantitative easing at the zero lower bound: structural var-based evidence from Japan. Journal of International Money and Finance, v. 33, p. 327-357, 2013.

TAN, J.; KOHLI, V. The effect of fed's quantitative easing on stock volatility. Social Science Research Network, June 2011. Disponível em: <https://ssrn.com/abstract=2215423>. Acesso em: 17 fev. 2018.

YELLEN, J. Communication in monetary policy. In: SOCIETY OF AMERICAN BUSINESS EDITORS AND WRITERS, 50., 2013, Washington. Speech... Washington: Board of Governors of the Federal Reserve System, 2013.

ZIVOT, E.; ANDREWS,D. W. K. Further evidence on the great crash, the oil-price shock, and the unit-root hypothesis. Journal of Business 8 Economic Statistics, v. 20, n. 1, p. 25-44, 2002.

\section{Apêndice A - Média e Variância Incondicionais de um Modelo AR()}

Formalmente, o modelo AR0 é dado por:

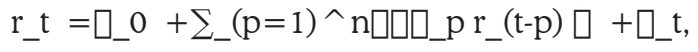

Calculando o valor esperado de ambos os lados, obtém-se:

$$
\begin{aligned}
& \mathrm{E}\left[\mathrm{r}_{-} \mathrm{t}\right]=\mathrm{E}\left[\square_{-} 0+\sum_{-}(\mathrm{p}=1) \wedge \mathrm{n} \square \square_{-} \mathrm{pr}_{-}(\mathrm{t}-\mathrm{p}) \square+\square_{-} \mathrm{t}\right] \\
& \mathrm{com} \mathrm{E}\left[\square_{-} \mathrm{t}\right]=0
\end{aligned}
$$




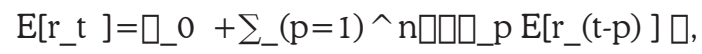

dado que $E\left[r_{-} t\right]=E\left[r_{-}(t-p)\right]=\mu$ :

$$
\begin{array}{r}
\mu=\square \_0+\sum_{-}(\mathrm{p}=1)^{\wedge} \mathrm{n} \square\left[\square \_\mathrm{p} \mu \square,\right. \\
\left(1-\sum_{p=1}^{n} \alpha_{p}\right) \mu=\alpha_{0}, \\
\mu=\frac{\alpha_{0}}{\left(1-\sum_{p=1}^{n} \alpha_{p}\right)^{\prime}}
\end{array}
$$

\section{Apêndice B - Média e Variância Incondicionais de um Modelo ARCH(p)}

Considere o seguinte modelo AR(p):

$$
\mathrm{r}_{\mathrm{t}}=+\mu+\mathrm{a}_{\mathrm{t}},
$$

no qual $r_{t}$ é o retorno do ativo no período t; $\mu$ é o modelo AR(p) estimado; e $a_{t}$ é uma sequência de variáveis aleatórias tal que $\mathrm{a}_{\mathrm{t}} \sim \mathrm{N}(0,1)$ i.i.d. Ademais, o resíduo do modelo, $r_{t}-\mu$, é definido como:

$$
a_{t}=\sigma_{t}^{2} \epsilon_{t}^{2},
$$

e é modelado a partir de um modelo $\mathrm{ARCH}(p)$, proposto por Engle (1982):

$$
\sigma_{\mathrm{t}}^{2}=\alpha_{0}+\sum_{\mathrm{p}}^{\mathrm{n}} \alpha_{\mathrm{p}} \sigma_{\mathrm{p}}^{2}
$$

sendo $\alpha_{0}>0$ e $\alpha_{1} \geq 0$ assegura variância positiva e $\alpha_{1}<1$ garante a estacionariedade. A variância incondicional de $a_{t}$ é:

$$
\operatorname{Var}\left(a_{t}\right)=E\left(a_{t}^{2}\right)-\left(E\left(a_{t}\right)\right)^{2}
$$

como $\mathrm{E}\left(\mathrm{a}_{\mathrm{t}}\right)=0$, pois $\mathrm{a}_{\mathrm{t}} \sim \mathrm{N}(0,1)$

$$
\operatorname{Var}\left(\mathrm{a}_{\mathrm{t}}\right)=\mathrm{E}\left[\sigma_{\mathrm{i}}^{2} \epsilon_{\mathrm{t}}^{2}\right]
$$

dado que $\mathrm{E}\left(\mathrm{a}_{\mathrm{t}}\right)=\operatorname{var}\left(\epsilon_{\mathrm{t}}\right)=1$ 


$$
\operatorname{Var}\left(\mathrm{a}_{\mathrm{t}}\right)=\mathrm{E}\left[\sigma_{\mathrm{i}}^{2}\right]
$$

substituindo (27) em (30):

$$
\begin{gathered}
\sigma_{t}^{2}=E\left[\alpha_{0}+\sum_{p}{ }^{n} \alpha_{p} a_{p}{ }^{2}\right], \\
\sigma_{t}^{2}=\alpha_{0}+E\left[\sum_{p}{ }^{n} \alpha_{p} a_{p}{ }^{2}\right], \\
\sigma_{t}^{2}=\alpha_{0}+E\left[\sum_{p}{ }^{n} \alpha_{p} \sigma_{t}^{2}\right], \\
{\left[1-\sum_{p}{ }^{n} \alpha_{p}\right] \sigma_{t}^{2}=\alpha_{0},} \\
\sigma_{t}^{2}=\alpha_{0} /\left(1-\sum_{p}{ }^{n} \alpha_{p}\right),
\end{gathered}
$$

\section{Apêndice C - Média e Variância Incondicionais de um Modelo EGARCHI}

A variância incondicional do modelo $\operatorname{EGARCH}(1,1)$ é apresentada abaixo.

$$
\log \left(\sigma_{\mathrm{t}}^{2}\right)=\gamma_{0}+\alpha_{1} \epsilon_{\mathrm{t}-1} / \sigma_{\mathrm{t}-1}+\gamma \epsilon_{\mathrm{t}-1} / \sigma_{\mathrm{t}-1}+\beta \log \left(\sigma_{\mathrm{t}-1}^{2}\right)
$$

multiplicando ambos os lados por $\sigma_{\mathrm{t}-1}^{2}$ :

$$
\sigma_{\mathrm{t}-1}^{2} \log \left(\sigma_{\mathrm{t}}^{2}\right)=\sigma_{\mathrm{t}-1}^{2} \gamma_{0}+\alpha_{1} \epsilon_{\mathrm{t}-1}+\gamma_{\mathrm{t}-1}+\sigma_{\mathrm{t}-1}^{2} \beta \log \left(\sigma_{\mathrm{t}-1}^{2}\right),
$$

extraindo o valor esperado em ambos os lados:

$$
\begin{gathered}
\left.\mathrm{E}\left[\sigma_{\mathrm{t}-1} \log \left(\sigma_{\mathrm{t}}^{2}\right)\right]=\mathrm{E}\left[\sigma_{\mathrm{t}-1}\right) \gamma_{0}+\alpha_{1} \epsilon_{\mathrm{t}-1}+\gamma_{\mathrm{t}-1}+\sigma_{\mathrm{t}-1} \beta \log \left(\sigma_{\mathrm{t}-1}^{2}\right)\right], \\
\sigma_{\mathrm{t}} \mathrm{E}\left[\log \left(\sigma_{\mathrm{t}}^{2}\right)\right]=\sigma_{\mathrm{t}} \gamma_{0}+\left(\alpha_{1}+\gamma\right) \mathrm{E}\left[\epsilon_{\mathrm{t}-1}\right]+\sigma_{\mathrm{t}} \beta \log \left(\sigma_{\mathrm{t}-1}^{2}\right),
\end{gathered}
$$

dividindo ambos os lados por $\sigma_{t}$ :

$$
\mathrm{E}\left[\log \left(\sigma_{\mathrm{t}}^{2}\right)\right]=\gamma_{0}+\left(\alpha_{1}+\gamma\right) \mathrm{E}\left[\epsilon_{\mathrm{t}-1}\right]+\beta \log \left(\sigma_{\mathrm{t}-1}^{2}\right),
$$

Como $\mathrm{E}\left[\epsilon_{\mathrm{t}-1}\right]=0$

$$
\begin{gathered}
E\left[\log \left(\sigma_{t}^{2}\right)\right]=\gamma_{0}+\beta \log \left(\sigma_{t-1}^{2}\right), \\
E\left[(1-\beta) \log \left(\sigma_{t}^{2}\right)\right]=\gamma_{0},
\end{gathered}
$$




$$
\begin{gathered}
E\left[\log \left(\sigma_{\mathrm{t}}^{2}\right)\right]=\gamma_{0} /(1-\beta), \\
E\left[\sigma_{t}^{2}\right]=e^{\frac{\gamma_{0}}{1-\beta},}
\end{gathered}
$$

Por fim, a volatilidade incondicional de um modelo $\operatorname{EGARCH}(p \quad q)$ é:

$$
E\left[\sigma_{t}^{2}\right]=e^{\frac{\gamma_{0}}{1-\sum_{\rho-1}^{n} \beta}},
$$

\section{Anexo D - Volatilidade Estimada}

Tabela 5 - Coeficientes estimados - modelo AR(p) - QE0

\begin{tabular}{cccccccc}
\hline Indicador & $\alpha_{1}$ & $\alpha_{1}$ & $\alpha_{2}$ & $\alpha_{3}$ & $\alpha_{4}$ & $\alpha_{5}$ & $\alpha_{6}$ \\
\hline Câmbio & $-1,05 \mathrm{e}-\mathrm{O} 5$ & $0,735^{*}$ & & & & & \\
Renda Fixa & $-1,03 \mathrm{E}-06$ & $0,653^{*}$ & & & & & \\
Risco-país & $1,70 \mathrm{E}-06$ & $0,579^{*}$ & & & & & \\
Juros EUA & $-4,22 \mathrm{E}-06$ & $1,02 \mathrm{E}+06$ & & & & & \\
IBOVESPA & $-2,39 \mathrm{E}-05$ & 0,291 & 0,221 & 0,061 & $-0,004$ & 0,124 & 0,078 \\
& $\alpha_{7}$ & $\alpha_{8}$ & $\alpha_{9}$ & $\alpha_{10}$ & $\alpha_{11}$ & $\alpha_{12}$ & $\alpha_{13}$ \\
IBOVESPA & -92 & 0,12 & 0,127 & 0,053 & 0,016 & 0,004 & 0,001 \\
\hline
\end{tabular}

Fonte: Elaboração própria 


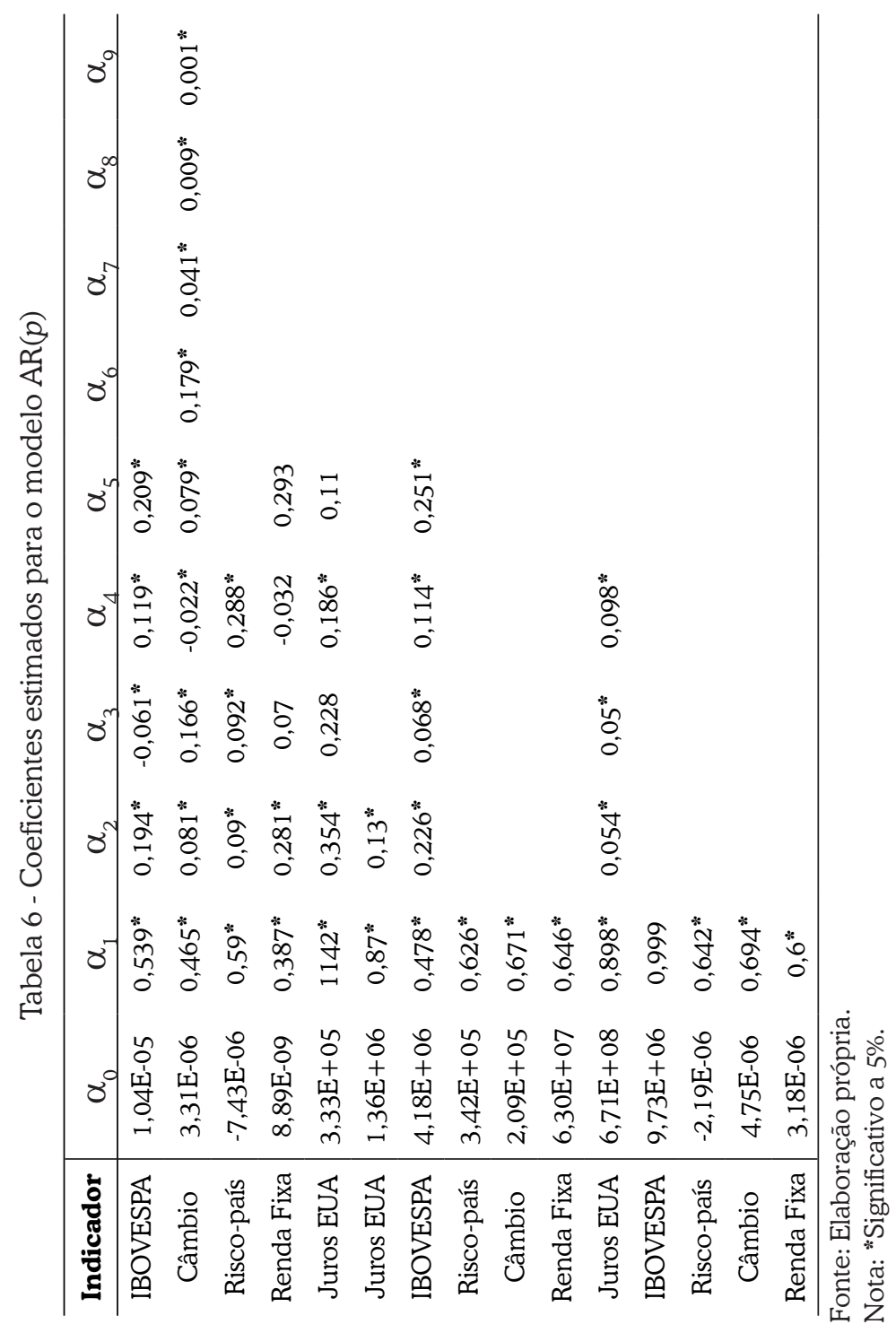




\section{Anexo E - Resultados encontrados para o Teste de Zivot and Andrews (2002) de Quebra Estrutural}

Figura 1- Resultados encontrados para o teste Zivot and Andrews (2002) de quebra estrutural
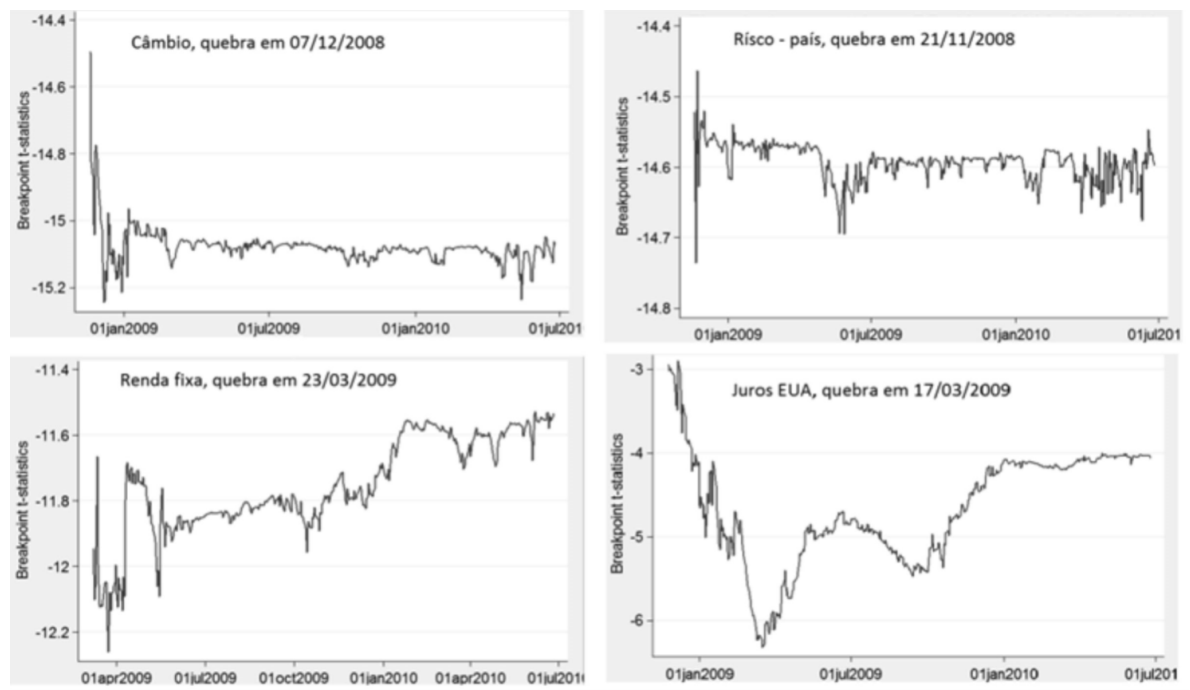

Fonte: Elaboração própria.

Figura 2- Resultados encontrados para o teste Zandrews de quebra estrutural

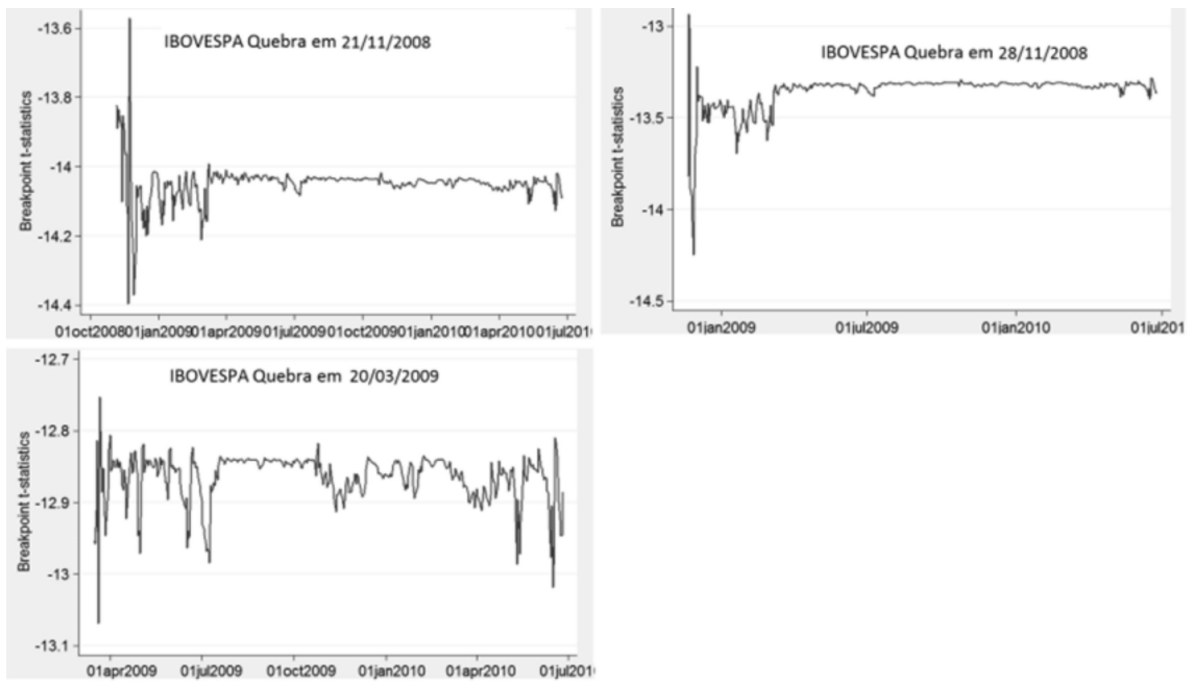

Fonte: Elaboração própria. 
Figura 3- Resultados encontrados para o teste Outlier inovacional (IO) e Outlier Aditivo (AO) de quebra estrutural, QE2
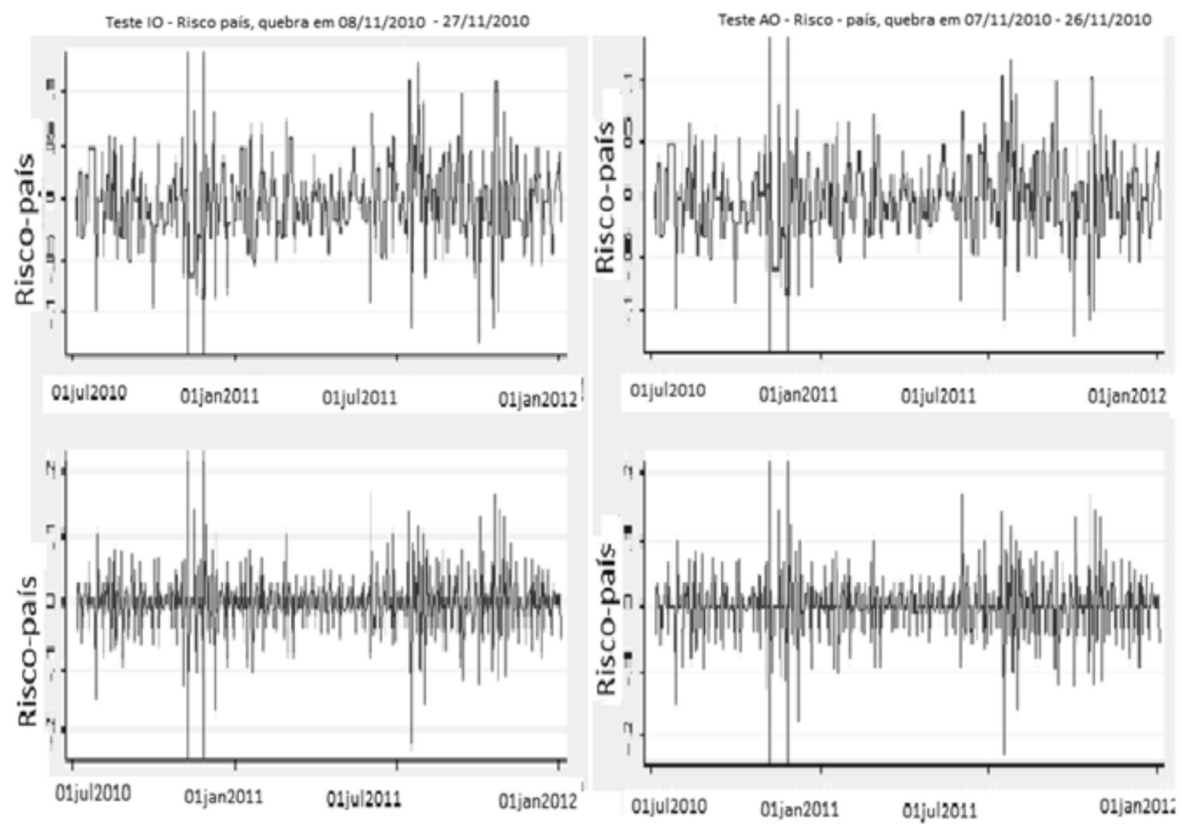

Fonte: Elaboração própria. 
Figura 4 - Resultados encontrados para o teste Outlier inovacional (IO) e Outlier Aditivo (AO) de quebra estrutural, QE1
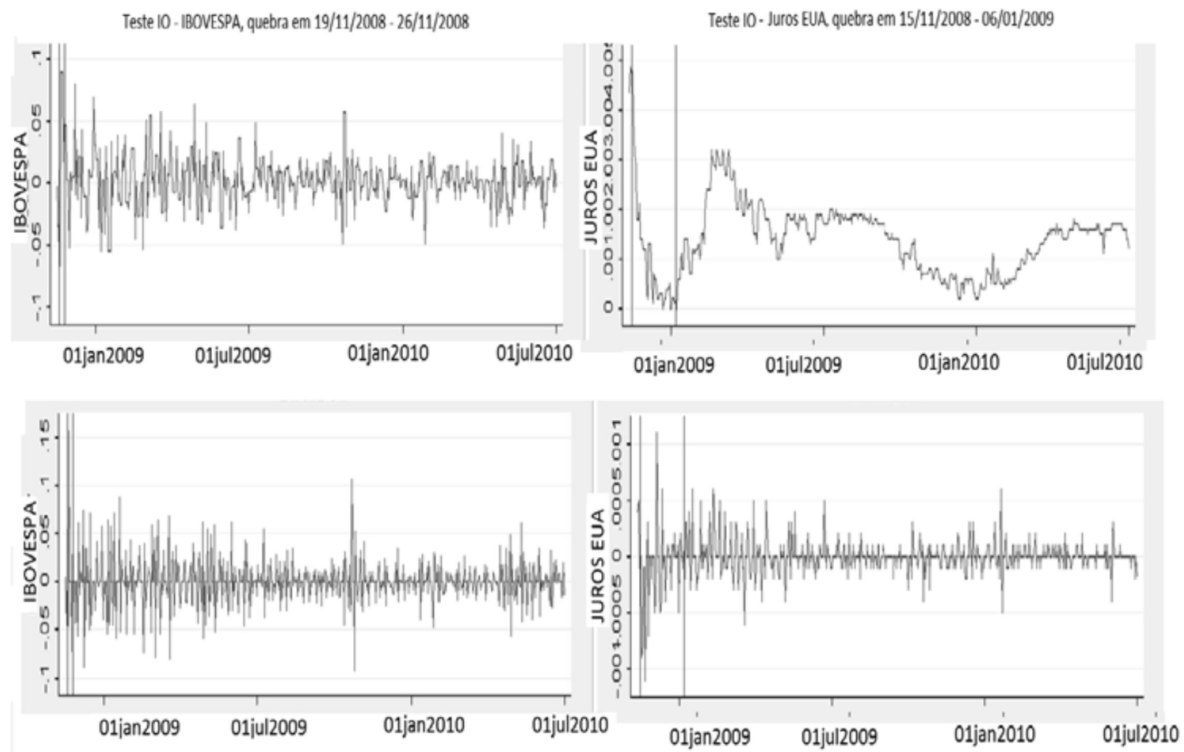

Teste AO-IBOVESPA, quebra em 18/11/2008-25/11/2008

Teste AO - Juros EUA, quebra em 03/02/2009-20/09/2009
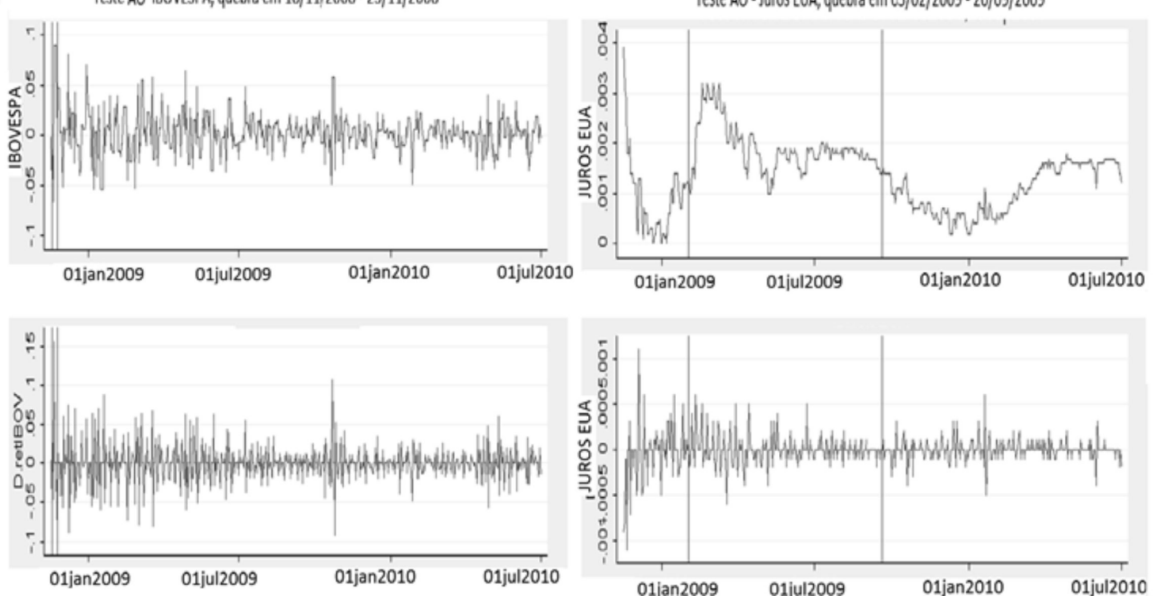

Fonte: Elaboração própria.

Recebido em: 23/03/2015.

Aceito em: 26/10/2016. 